\title{
COVID-19 response strategies: considering inequalities between and within countries
}

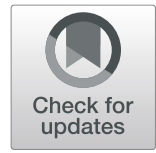

Lincoln Leehang Lau ${ }^{1,2,3^{*}}$ (D) Natalee Hung ${ }^{1}$ and Kendall Wilson ${ }^{1}$

\begin{abstract}
Globally, the COVID-19 pandemic has been uncharted territory, and countries and governments have faced the challenge of implementing response strategies to manage local transmission. High-income settings have the resources to devote significant resources to testing, isolation, and contact tracing. Lower-income settings are pressured to emulate such initiatives, but often lack the resources and infrastructure to do so. We highlight the impact of these between-country inequalities, the within-country inequalities, and the potential magnification of unintended consequences due to COVID-19 control measures.
\end{abstract}

Keywords: COVID-19, LMICs, Pandemic response, Inequalities

\section{Background}

Since the emergence of the novel coronavirus disease 2019 (COVID-19), policy makers and governments have had to make important decisions around what mitigation and control measures to implement. Given initial uncertainties about the nature of the disease, responses were varied country to country. Over time, three strategies have become recognized as the "backbone" of the response to COVID-19: testing, isolation and contact tracing [1]. In certain countries, these measures appear to have contributed to reductions in the incidence of COVID-19 [2]. Many low- and middle-income countries (LMICs), however, do not have the resources nor the infrastructure to emulate such initiatives to the same extent, and yet may feel pressured to do so. There is a need to consider the inequalities that exist, both between countries and within countries, and ensure that response strategies are appropriate to the capacity of each jurisdiction.

* Correspondence: lincoln.lau@caremin.com

${ }^{1}$ International Care Ministries Inc, Manila, Philippines

${ }^{2}$ Dalla Lana School of Public Health, University of Toronto, Toronto, Canada

Full list of author information is available at the end of the article

\begin{abstract}
Main text
Between-country inequalities

These, perhaps unrealistic, pressures have been visible in the Philippines. Initially, the government responded by enforcing strict home quarantines and a lockdown on business and transportation in regions with significant COVID-19 cases. More recently, the focus has turned towards scaling-up national capacities for mass testing, with the expectation that the Philippines should follow in the example of other Asian countries. Researchers in the Philippines have commended Singapore and South Korea's successful suppression of the reductive number by increased testing and contact tracing [3]. In another report by the University of Philippines, authors made recommendations to expand nationwide testing capabilities to a capacity similar to that of South Korea [4] but it is difficult to see how this would be feasible in the Philippines. Beyond the procurement of COVID-19 test kits, mass testing would require substantial investment in equipment, lab facilities, and manpower. However, health expenditure per capita in South Korea in 2017 was USD $\$ 2283.07$, compared to USD $\$ 132.90$ in the Philippines [5]. South Korea has established almost 600 COVID-19 testing centres [6], and the Philippines currently has 58 [7]. Although the Philippines has been able
\end{abstract}


to gradually expand testing capacity, with only 10 tests conducted per 100,000 population on June 16, 2020, compared to 27 tests per 100,000 population in South Korea on the same day (Fig. 1a), it is evident that the two countries are on different playing fields. The government is seeking to adopt measures that seem to be successful in other countries, but should give due consideration to the constraints and the betweencountry inequalities that may prevent them from achieving similar outcomes.

\section{Within-country inequalities}

We highlight not only the inequalities between countries, but the disparities that are further magnified when we look within countries and toward regions that have less resources. Local government units (LGUs) have been expected to enforce measures that are consistent with those in the National Capital Region (NCR), but the geographical, social and economic landscape from which these directives originate often differ from the rural communities in which they are meant to be implemented. While $12 \%$ of the nation's population lives within NCR, the region accounts for $36 \%$ of the total GDP [8]. Just as the Philippines lacks the resources and infrastructure to match South Korea's COVID-19 response, regions outside of NCR likewise do not have the resources to replicate the proposed ambition of mass testing in the capital region. Between April 3 and June
16, 2020, 75.5\% of all COVID-19 tests were conducted in NCR, and Fig. 1b compares the daily number of tests per 100,000 population that were conducted by location. We note that before regions were assigned COVID-19 labs within a 'zoning area' on April 23 [9], all specimens were tested in NCR, even if they originated from individuals elsewhere. However, the gap in testing capacity has since continued to widen, and the difference in number of tests conducted daily per 100,000 population is now almost tenfold.

Another pressing challenge in light of these inequalities are the other health issues that will persist, if not be exacerbated by this public health emergency [10]. The expansion in testing capacity achieved within NCR has been resource intensive, facilitated by public and private sector investment. However, given persisting resource limitations, many tuberculosis (TB) testing facilities have been reconfigured for COVID-19 testing in order to meet demands [11]. These facilities were already limited in regions outside of NCR, but due to resource disparities and the pressure to keep up with the capital region, LGUs have implemented COVID-19 control strategies at the expense of other disease control initiatives. Without proper and timely guidance, many local governments are left to copycat national measures that may be ill-fitting to their communities with resulting social and economic consequences. If the repercussions of ineffective responses could be compounded by unintended harms, it

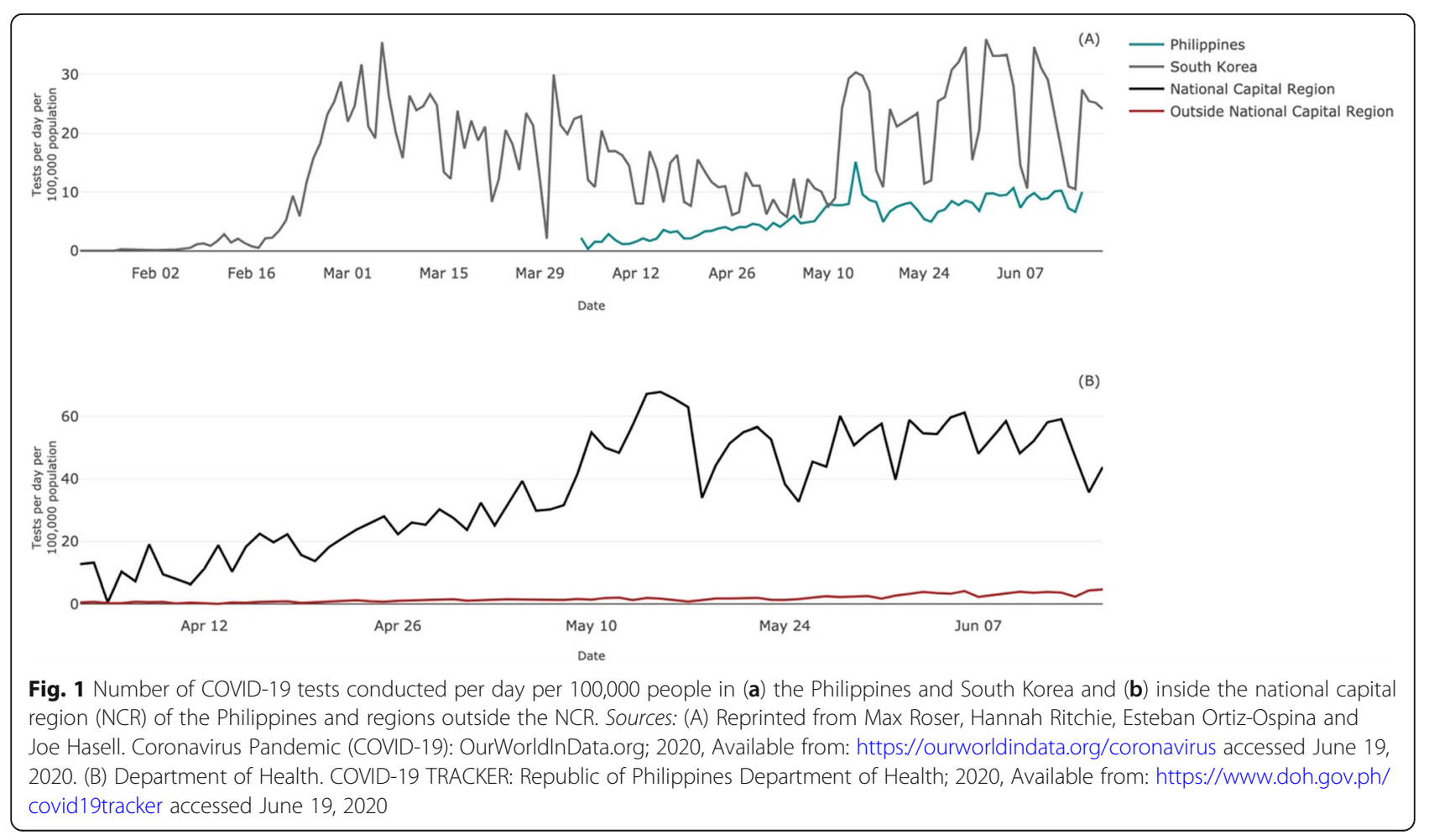


is imperative that due consideration is given to what LGUs are capable of doing given local resource constraints.

\section{Conclusions}

In an analysis of the challenges the Philippines has faced raising testing capacity [12], we agree with the authors' appeals for the integrity of testing to be upheld despite pressures to rapidly scale up. Increasing testing capacity without compromising quality, however, requires technical capacity and significant resources. This raises the question: in regions that do not have the means, what should they do? Given inherent disparities in how resources are distributed, countries should not be treated homogenously when designing national response strategies. While there has been increasing recognition that COVID-19 response strategies need to be contextspecific, discussions have primarily been focused on the national level, while differences within the country have tended to be overlooked. The global health community must be sensitive to both between and within-country inequalities as formal guidance for low-resource contexts are developed.

National and local governments have been under immense pressure to act and contain the virus, but inappropriately copying approaches could create more unintended harm than good. We have highlighted the observed and anticipated disparities in COVID-19 testing, but other aspects of COVID-19 responses also warrant further exploration. While the fight against COVID-19 is far from over, we need to appreciate between- and withincountry inequalities to formulate appropriate, rather than reactionary, pandemic management strategies.

\section{Abbreviations}

COVID-19: Coronavirus disease 2019; LMICs: Low- and middle-income countries; LGUs: Local government units; NCR: National Capital Region

\section{Acknowledgements}

The authors thank Daryn Joy Go, Mia Choi, and Hannah Ferrolino for data assistance, and Ben Cowling and Wu Peng for helpful discussion.

\section{Authors' contributions}

LLL conceived, wrote and edited the manuscript. NH wrote and edited the manuscript. KW contributed to data visualisation. All authors read and approved the final version.

\section{Funding}

None.

\section{Availability of data and materials}

All data are publicly available through the Our World in Data and the Republic of Philippines Department of Health website.

\section{Competing interests}

The authors declare that they have no competing interests.

\section{Author details}

${ }^{1}$ International Care Ministries Inc, Manila, Philippines. ${ }^{2}$ Dalla Lana School of Public Health, University of Toronto, Toronto, Canada. ${ }^{3}$ School of Public Health and Health Systems, University of Waterloo, Waterloo, Canada.

Received: 22 July 2020 Accepted: 5 August 2020

Published online: 12 August 2020

\section{References}

1. World Health Organization. WHO Director-General's opening remarks at the media briefing on COVID-19 - 16 March 2020 Geneva: WHO; 2020 [May 2, 2020]. Available from: https://www.who.int/dg/speeches/detail/whodirector-general-s-opening-remarks-at-the-media-briefing-on-covid-19\%2 D\%2D-16-march-2020.

2. Kucharski AJ, Klepac P, Conlan AJK, Kissler SM, Tang ML, Fry H, et al. Effectiveness of isolation, testing, contact tracing, and physical distancing on reducing transmission of SARS-CoV-2 in different settings: a mathematical modelling study. Lancet Infect Dis. 2020. https://doi.org/10. 1016/S1473-3099(20)30457-6 PubMed PMID: 32559451.

3. UP COVID-19 Pandemic Response Team. Modified Community Quarantine beyond April 30: Analysis and Recommendations: University of Philippines; 2020 [May 2, 2020]. Available from: https://www.up.edu.ph/modifiedcommunity-quarantine-beyond-april-30-analysis-and-recommendations/.

4. David G, Rye RS, Ma Patricia Agbulos. COVID-19 FORECASTS IN THE PHILIPPI NES: Sub-National Models for NCR and other Selected Areas: University of Philippines; 2020 [May 2, 2020]. Available from: https://www.up.edu.ph/wpcontent/uploads/2020/04/April-29-UP-OCTA-research-Covid-19-in-thePhilippines-forecast-report-No.5_eaa.pdf.

5. The World Bank. Current health expenditure per capita (current US\$): The World Bank Group; 2017 [May 2, 2020]. Available from: https://data. worldbank.org/indicator/SH.XPD.CHEX.PC.CD.

6. Ministry of Health and Welfare. 19

(Corona 19 Screening Clinic and National Security Hospital) 2020 [June 16, 2020]. Available from: https://www.mohw.go.kr/react/popup_2 00128 3.html.

7. Department of Health. COVID-19 TRACKER: Republic of Philippines Department of Health; 2020 [May 2, 2020]. Available from: https://www.doh. gov.ph/covid19tracker.

8. Philippine Statistics Authority. Regional Economy of the National Capital Region (NCR) in 2018: Philippines Statistics Authority; 2019 [June 22, 2020]. Available from: http://rssoncr.psa.gov.ph/article/regional-economy-nationalcapital-region-ncr-2018.

9. Department of Health. Interim Guidelines on the Zoning of COVID-19 Laboratories: Republic of Philippines Department of Health; 2020 [May 18, 2020]. Available from: https://www.doh.gov.ph/sites/default/files/healthupdate/dm2020-0188.pdf.

10. Stop TB Partnership. We did a rapid assessment: THE TB RESPONSE IS HEAV ILY IMPACTED BY THE COVID-19 PANDEMIC: Stop TB Partnership; 2020 [Jul 6, 2020]. Available from: http://www.stoptb.org/news/stories/2020/ns20_014. html.

11. Department of Health. Designation of Selected Regional TB Culture Laboratories for GeneXpert Diagnosis of Coronavirus Disease 2019 (COVID19): Republic of Philippines Department of Health; 2020 [May 18, 2020]. Available from: https://www.doh.gov.ph/sites/default/files/health-update/ dm2020-0191.pdf.

12. Nuevo CE, Sigua JA, Boxshall M, Co PAW, Yap ME. BMJ GH Blogs. 2020. [cited June 5, 2020]. Available from: https://blogs.bmj.com/bmjgh/2020/06/ 05/scaling-up-capacity-for-covid-19-testing-in-the-philippines/.

\section{Publisher's Note}

Springer Nature remains neutral with regard to jurisdictional claims in published maps and institutional affiliations.

Ethics approval and consent to participate

Not applicable. 